\title{
Article
}

\section{What do counsellors need to know about male depression?}

\author{
Athanasiadis, Chrysostomos, Gough, Brendan and Robertson, \\ Steve \\ Available at http://clok.uclan.ac.uk/18803/ \\ Athanasiadis, Chrysostomos, Gough, Brendan and Robertson, Steve (2018) \\ What do counsellors need to know about male depression? British Journal of \\ Guidance and Counselling, 46 (5). pp. 596-604. ISSN 0306-9885
}

It is advisable to refer to the publisher's version if you intend to cite from the work. http://dx.doi.org/10.1080/03069885.2017.1346232

For more information about UCLan's research in this area go to http://www.uclan.ac.uk/researchgroups/ and search for < name of research Group>.

For information about Research generally at UCLan please go to http://www.uclan.ac.uk/research/

All outputs in CLoK are protected by Intellectual Property Rights law, including Copyright law. Copyright, IPR and Moral Rights for the works on this site are retained by the individual authors and/or other copyright owners. Terms and conditions for use of this material are defined in the policies page.

\section{CLoK}

Central Lancashire online Knowledge www.clok.uclan.ac.uk

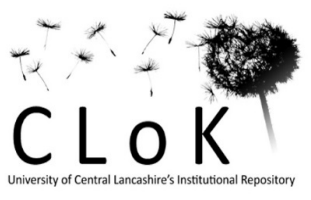




\title{
Suggested title: What do counsellors need to know about male depression?
}

\section{Lead author: Chrysostomos Athanasiadis \\ Address:}

Division of Counselling and Psychological Therapies

School of Community Health and Midwifery

University of Central Lancashire

Preston

PR1 2HE

Email: cathanasiadis@uclan.ac.uk

Tel: 0044 (0)1772 893776

\author{
Second author: Professor Brendan Gough \\ Leeds Beckett University \\ City Campus, Leeds \\ LS1 3HE \\ Email: b.gough@leedsbeckett.ac.uk \\ Tel: $0044(0) 1138123934$
Leeds Beckett University
City Campus, Leeds
LS1 3HE
Email: s.s.robertson@leedsbeckett.ac.uk \\ Third author: Professor Steve Robertson \\ Tel: 0044 (0)113 8124359
}

\section{Biographies}

Chrysostomos Athanasiadis is a BACP-registered counsellor and a chartered psychologist. He is currently Lecturer in Counselling and Psychological Therapies at the University of Central Lancashire.

Brendan Gough is Professor of Social Psychology at Leeds Beckett University. He has research interests in critical social psychology, in qualitative methods and in men and masculinities.

Steve Robertson is Professor of Men, Gender and Health and Co-Director of the Centre for Men's Health at Leeds Beckett University. His main research interests are on social theories of gender and masculinities and their application to aspects of health and illness.

Submitted for publication in:

British Journal of Guidance and Counselling

First submission: July 2016

First re-submission: 1 March 2017

Second re-submission: 18 April 2017

Third re-submission: 22 May 2017

Word count: 5726 (including references)

This paper has not been published elsewhere and it not under consideration for publication elsewhere.

The authors report that there is no conflict of interest in respect of this publication. 


\title{
Suggested title: What do counsellors need to know about male depression?
}

\begin{abstract}
The lower reported prevalence of depression in men has been related to depression not being as well-recognised in men as it is in women. We sought to understand the clinical under-recognition of depression in men by reviewing some of the key evidence on male depression, concentrating on practices in the UK. Additionally, we aimed to draw conclusions that would contribute to the improvement of health promotion and of the diagnosis for male depression. Our perusal of the available evidence has revealed that some depressed men experience significant difficulties not only in disclosing but also in identifying their depression and that men often exhibit atypical symptoms such as anger. Furthermore, depressed men are often involved in attempts to self-manage their depressive symptoms. This stoic approach compromises the wellbeing of depressed men and it discourages them from accessing appropriate support resources. We conclude with suggestions for practice and research.
\end{abstract}

Key words: Male depression; atypical depression; masculinity and depression; men's help-seeking; clinical implications of male depression.

\section{The prevalence of male depression}

The lower incidence rate of depression in men has been confirmed consistently over the years (e.g. Addis, 2008; Piccinelli \& Wilkinson, 2000; Fields \& Cochran, 2011). Recent epidemiological evidence shows that in 2009/10 11\% of adults in England were diagnosed with depression (Office for National Statistics, 2011). The available evidence refers to depression data that has been merged with anxiety data. The overall reported prevalence for 'depression or anxiety' appears to be higher for 45- to 54year-old men and women (22.8\%), whereas it is the lowest for ages 65 to 74 (14.4\%) (Office for National Statistics, 2016). The Office for National Statistics draws on data from the UK Household Study $2010(n=40000)$ and reports that depression and anxiety are more common in men (18.25) and in women (21.5\%) for age groups 40-59 (Office for National Statistics, 2016). For men, specifically, the incidence rate is higher for age groups 45-49 (19\%) and 50-54 (20\%) (Office for National Statistics, 2016). Interestingly, evidence about suicide rates shows that in 2009 suicide was highest among males aged 15 to 44 years (18.0 per 100,000) and among females aged 45 to 74 years (5.8 per 100,000) (Office for National Statistics, 2016).

This evidence becomes difficult to interpret especially with respect to men since men appear to be attempting suicide at a period of their life for which depression and anxiety have not been shown to be at their peak. This may be indicating that if depression is present in those men who commit suicide, then it may not be identified accurately. In turn, this finding may be supporting the suggestion in the scientific literature that: (a) men may not be recognising their depression (Sharpley, Bitsika, \& Christie, 2014) and (b) men find it difficult to express their feelings (e.g. Rutz, Von Knorring, Pihlgren, 
Rihmer, \& Walinder, 1995). On both occasions, men would be unlikely to externalise their depression and to seek help about it. Additionally, men may be experiencing and manifesting depression in unconventional ways which may go unnoticed by others (Smith et al., 2008), including healthcare professionals (Sharpley et al., 2014; Sharpley, Bitsika, \& Christie, 2016).

Clearly, there is a need to improve our understandings of depression in men and this proposition has formed the impetus of the present paper. We aimed to review some of the key evidence on manifestations of male depression with a view to reaching new understandings that could contribute to the improvement of diagnosis and of health promotion initiatives that target depressed men. Due to limitations of time and resource, and since our scope was quite broad and our priority was to review and summarise rather than to more formally evaluate evidence, we decided that a scoping review (Arksey \& O'Malley, 2005) rather than a detailed systematic review would best help us meet our aims. We collected information until the end of October 2016 and from the following databases: Medline, PsycINFO, Research Starters and CINAHL Complete. We share our conclusions with the readers of our paper and we demonstrate the atypicality of some symptoms of depression in men through the use of a vignette. We hope that our discussion will stimulate debate and further research.

\section{The diagnosis of depression in men}

The lower reported prevalence of depression in men raises questions as to whether the diagnostic process fails to adequately recognise depression in men (Rutz et al., 1995; Sharpley et al, 2016). It is likely that the inconspicuous focus of diagnostic systems on the clinical presentation of depression in women may be detracting from the potentially different manifestation of depression in men (Brownhill et al., 2005). Men have been reported to exhibit atypical symptoms of depression such as irritability, alcohol and substance abuse, difficulty exercising self-control (Sharpley et al., 2014), somatic symptoms and anhedonia (Sharpley et al, 2016). We would like to demonstrate the difficulties in diagnosing atypical depression in men with the use of the following hypothetical vignette:

$\mathrm{Jez}^{1}$, a 30-year-old male fitness instructor has worked in a fitness centre for three years. He is also a keen martial arts athlete and he has won awards in martial arts competitions around the country. Jez has been enjoying his job at the gym where he is liked and respected for his skills. He has been getting on with everyone up until the time when his marriage ended three months ago. People in his work environment noticed that his social skills had declined. A number of gym members complained about Jez's often sarcastic comments during their personal training sessions. Additionally, members of staff reported that Jez would "jump down their throat" if anything was said that he did not agree with. During this period, Jez requested sick leave due to an upset gut and abdominal pain. He visited his GP$^{2}$ who suggested that Jez's physical symptoms were concordant with the clinical manifestations

\footnotetext{
1 'Jez' is a fictitious male character who presents with an atypical manifestation of depression. ${ }^{2}$ In the UK, General Practitioners are entrusted with diagnosing common mental health difficulties (Royal College of Psychiatrists, 2014).
} 
of IBS and she recommended a change in diet and pharmacological management of his gastrointestinal symptoms.

It is unlikely that most healthcare (including mental health) practitioners would conceptualise Jez's condition as signifying the experience of depression since Jez's symptoms do not resonate with either Major Depressive Episode or with Major Depressive Disorder. A diagnosis of depression would normally be expected to account for, at least partly, other more typical symptoms of depression, such as: low mood, persistent hopelessness or decreased interest in everyday pleasurable activities (Sharpley et al., 2014). In addition, the somatic manifestations that, essentially, encouraged Jez to visit his GP would draw any medical practitioner to consider (and to try and rule out) a pathological cause (Hoy, 2012).

Jez's case scenario is an example of a case of male depression where depressive symptoms do not confidently fit standard diagnostic criteria for depression. We specifically chose the case of a man who is not at the age range of $45-54$ years of age where depression in men is statistically most likely to occur according to the Office for National Statistics (Beaumont \& Lofts, 2013). This, along with the absence (or non-report) of other typical symptoms of depression, and whilst Jez appears to have an active lifestyle, would most likely dissuade healthcare professionals from considering depression (Hoy, 2012). Jez's outlook is that of a young, dynamic, aspiring and hard-working man. Jez's occupational background requires him to be active, to plan and deliver physically demanding fitness classes and personal training sessions. This level of activity requires energy and the daily expenditure of effort both of which are thought to be uncharacteristic of depressed people who are, normally, expected to have low levels of activity (Brownhill, Wilhelm, Barclay, \& Schmied, 2005). Therefore, it is reasonable suggestion that Jez's anger may not be recognised as a sign of depression in a routine examination.

\section{Atypical symptoms of depression}

It is conceivable, then, that some depressed men express their depression in atypical ways and that this makes it difficult for current diagnostic systems to identify those symptoms as concurrent with depression. For example, the scientific literature has for some time now identified anger as one of the atypical symptoms of depression in men (Smith et al., 2008). Nevertheless, the diagnostic systems in use today (e.g. DSM and ICD) still do not list anger as a typical manifestation of major depressive disorder. However, DSM-5 criteria now state 'irritability' in addition to 'low mood' (APA, 2013), and the NHS website now includes the symptom: 'feeling irritable and intolerant of others' (National Health Service, 2014, August 19). This is in line with research evidence that demonstrate the predominance of irritability amongst male symptoms of depression (Sharpley et al, 2014; 2016). Additionally, there have been attempts to develop male-specific measure of depression such as the Gotland Scale for Assessing Male Depression (Zierau, Bille, Rutz, \& Bech, 2002) which has successfully shown some male-specific symptoms (Sharpley et al., 2014; 2016). 
On the basis of current diagnostic guidelines, Jez's anger would most likely not be seen as an indication that Jez may be experiencing emotional or psychological difficulties - especially since the diagnostic criteria for depression are based on typical symptoms of depression in women, which tend to emphasise low mood and reduced levels of activity (Brownhill et al., 2005). Considering the existing narrow definitions used to capture the prevalence of depression, it is not surprising that depression is reported to be less prevalent in men than in women (e.g. Addis, 2008). As a consequence of this, the different clinical presentation of depression in Jez and in other men may be overlooked or misinterpreted, thus leading to male depression being underdiagnosed (Brownhill et al., 2005) and depressed men not getting the professional care that they need (Ramirez \& Badger, 2014).

An additional impediment in the diagnosis of depression in men is the documented difficulty that many men have in externalising their emotions (e.g. Addis \& Mahalik, 2003). There has been speculation in the scientific literature about this being related to masculine role socialisation (Courtenay, 2000) which thwarts the acquisition of skills, by men, in expressing or in recognising their emotions (Ridge, Emslie, \& White, 2011). In extreme cases, this can result in total dissociation from one's emotional world what Levant (1998) has termed normative male alexithymia. However, more recently, research has demonstrated that the lower incidence rate of depression in men may be due to depressed men's inhibitions in disclosing their condition, as a function of their perception of others' reactions to their disclosure (Galasiński, 2008; Gough, 2016). Sportsmen, like Jez, who take part in competitive sports are alleged to have insuperable difficulties in talking about their depression (Mind, n.d.). Ironically, it is usually men who hold the most negative attitudes towards help-seeking that are often most at risk for developing depression as their unwillingness to externalise their emotions restricts their access to support networks (Ellis et al., 2013; Rochlen et al., 2010).

\section{Self-awareness of symptoms}

Evidently, for a person to be able to share their emotional needs and concerns they need to be able to recognise that they have certain emotional needs and concerns. Regrettably, depressed men are not as good at either identifying or accepting their own symptoms of depression (Sierra Hernandez, Han, Oliffe, \& Ogrodniczuk, 2014). The recognition of depression by men is often hampered by men viewing their symptoms as inherent parts of their personality (Epstein et al., 2010). For example, men may consider moodiness or anger or diminished ability to experience pleasure as just the way they are as a person, considering such characteristics to be traits of their personality or of the masculine role. Furthermore, men may discount the more conventional symptoms of depression due to the perceived incompatibility of such symptoms with traditional masculine roles (Rochlen et al., 2010). Additionally, depressed men may be dismissing the importance of their symptoms because they are unaware of the complex nature of their condition and the fact that it is not just a state of being unhappy (Rochlen et al., 2010). This may lead depressed men to cope with their depression stoically, unlike women who may be more prepared to share their experience of depression with other people (Brownhill et al., 2005; Fields \& Cochran, 2011). In light of men's stoic approach, it is not surprising that men are less likely to recommend that a depressed person sees a mental health professional 
(Klineberg, Biddle, Donovan, \& Gunnell., 2011). Men's recognition of their depression is further complicated by masculine ideals which value stoicism and emotional control (Addis \& Mahalik, 2003) and which encourage men to self-manage their difficulties (Sloan, Gough, \& Conner, 2010).

\section{Obstacles to men's help-seeking}

Suggestions in the literature appear to draw clear links between male depression and the social construction of masculinity. If depressed men find it difficult to communicate their depression then how are they managing their depression? Research has shown that a male identity is achieved through "identification with male gender and the construct of 'masculinity' (examples include but are not limited to: toughness, stoicism, action-orientation, risk-taking)" (Robertson, Bagnall, \& Walker, 2014, p. 7). Men ordinarily fulfil masculine ideals by showing strength and dominance (Courtenay, 2000; Fields \& Cochran, 2011; Sierra Hernandez et al., 2014). This is eloquently reflected in Robertson's (2006, cited in Ridge et al., 2011, p. 154) suggestion that “men 'do' gender when they are giving others the impression that they are not 'doing' health, especially mental health". In other words, men often construct their masculinity by adopting behaviours that show defiance. Therefore, men's dismissal of their health needs becomes a measure of how well they fit the masculine role.

Additionally, men are frequently faced with disbelief when they disclose their depression (Gough, 2016; Ramirez \& Badger, 2014), possibly, as a function of masculine roles. Nevertheless, this leaves men feeling rejected and isolated (Ramirez \& Badger, 2014). It also possibly results in the externalisation of depression in men in ways that reflect compliance with conventional idealised masculinities (Oliffe, Galdas, Han, \& Kelly, 2012). For example, men may be expressing their depression as anger or through somatic symptoms (Addis, 2008; Addis \& Mahalik, 2003; Hoy, 2012), as is the case with Jez in the aforementioned client scenario. Alternatively, depressed men may be resorting to the use of psychotropic substances or alcohol (Addis, 2008; Ridge et al., 2011) or other risk-taking behaviour (Lester, 2014) or even by isolating themselves (Oliffe et al., 2012). Such unhealthy practices are a way of showing defiance, resilience, autonomy and strength (Sloan et al., 2010).

Contrary to earlier suggestions about the role of masculinity norms, depressed men's hesitation with seeking help may not be related to an inability to recognise the symptoms of depression or to a lack of knowledge of sources of help but to public sigma (McCusker \& Galupo, 2011) and to self-stigma (Hoy, 2012; Klineberg et al., 2011; Latalova, Kamaradova, \& Prasko, 2014; Martinez-Hernaez, DiGiacomo, Carceller-Maicas, Correa-Urquiza, \& Martorell-Poveda, 2014).

Research has confirmed that men who choose to disclose their depression or who are proactive in seeking psychological help for it are perceived as possessing fewer masculine and more feminine characteristics than men who cope on their own (McCusker \& Galupo, 2011). Such widely propagated stereotypes permeate cultural values and help construe help-seeking as not typical of men (O'Brien, Hunt, \& Hart, 2005) further hindering a proactive approach to addressing depression. Unsurprisingly, 
men who internalise such stereotypical views develop negative representations of depression in the form of self-stigma (Coppens et al. 2013) and this leads them to associate help-seeking with loss of control over their lives (Vogel \& Wade, 2009). In turn, this discourages depressed men from recognising the significance of their symptoms and from seeking professional help about their condition (Möller-Leimkühler, 2002). This finding demonstrates the necessity to help depressed clients of psychological services address internalised feelings of shame. Additionally, it shows that action is required to help change public attitudes that may affect depressed men's decision to seek help for their depression.

\section{Age-specific attitudes to help-seeking}

So far, we have established the strong possibility that some depressed men may be reluctant to seek help since seeking help may be construed as unmasculine. However, could this be true for men for all age groups? Certainly, older men, have been reported to be prone to depression since retirement and age-related frailty can lead to loss of the experience of being productive and of having control over one's live (Apesoa-Varano, Barker, \& Hinton, 2015). Evidence from a study of depressed Canadian men aged 55-82 has confirmed the importance of maintaining masculine roles fit ideals such as being a provider for one's family for this age group (Oliffe et al., 2013).

Therefore, a general recommendation for older men who are depressed would be for them to be encouraged to redefine their masculinity through activities which are complimentary to paid work such as volunteering and pursuing a hobby or special interest. Such activities afford men opportunities for emotional expressiveness and for caring for others thus helping men fulfil "egalitarian" roles (Oliffe et al., 2013, p. 1634). These roles can help older men harmonise their espoused traditional male ideals with contemporary masculine role expectations (Gough, Hall, \& Seymour-Smith, 2014). It is likely that the redefinition of masculinity may help older men make help-seeking part of their gender identify and thus acceptable (Sierra Hernandez et al., 2014) since help-seeking can be seen as a sign of resilience (Tannenbaum \& Frank, 2011). Additionally, getting professional help and following a recommended intervention may be suitably empowering to a man by way of inducing a sense of being in control (Robertson et al., 2014; Sierra Hernandez et al., 2014).

\section{Depression in younger men}

Depression appears to be present in younger men, too, only for different reasons. In one study, men of 17-21 years of age perceived depressive symptoms as part of everyday life (Martinez-Hernáez et al., 2014). This may be signifying an attempt to normalise depressive symptoms in order to feel normal and accepted. The normalisation of depressive symptoms for younger people is supported by a study of clinically depressed 17-25-year-old Swedish men and women where participants expressed a desire to be normal in order to safeguard self-esteem, security and acceptance (Danielsson, Bengs, Samuelsson, \& Johansson, 2011). The desire to protect identity from the threat of depression is often so great that men, as well as women, may delay seeking help for their depression using a number of 
avoidance strategies until they have accepted their depressive symptoms as a normal part of themselves (Farmer, Farrand, \& O'Mahen, 2012).

Younger depressed men appear to be avoiding seeking help owing to the perceived threat that depression poses for their ability to conform to masculinity norms (Sierra Hernandez et al., 2014). This is a conceivable reason for younger men's preference for self-help (Ellis et al., 2013). Being perceived as not conforming to widely held, culturally prescribed, masculinity norms may be detrimental to a young man's ability to continue to be part of peer groups (Addis \& Mahalik, 2003). These are important observations as they may be signifying that mental health campaigners need to be working constructively with masculine roles in order to succeed in encouraging depressed men to seek psychological help.

\section{Clinical implications}

It has been argued earlier in this paper that depressed men who espouse traditional masculine roles unquestionably may be finding it harder to seek professional help for their depression since both depression and help-seeking are considered by men to be incompatible with traditional masculine norms (Addis, 2008).

Arguably, depressed men who subscribe to traditional masculine norms are more likely to try and cope on their own (Latalova et al., 2014). However, by self-managing their depression, men are placing themselves, their dependants and people who care for them under unwarranted emotional duress whilst not benefiting from available specialist support. Therefore, it becomes imperative for all of us who work in the area of mental health to help sever this vicious cycle of events and to help eradicate common misconceptions about male depression and men's help-seeking. By the mere nature of our work, all of us who work in mental health, and in healthcare, at large, are best placed to lead in educating our male clients, people in their immediate support system and the wider public. We need to proliferate the message that depression can and does affect anyone, including men of any age, ethnic background, educational level and socio-economic status.

Additionally, all those of us who work as practitioners need to be closely observant of our male clients who are showing signs of anger, substance dependency, risky behaviours or who may be isolating themselves or working long hours or not eating healthily or who are experiencing medically unexplained somatic symptoms since any of these behaviours could be underpinned by depression. Helping potentially depressed male clients recognise their depression involves encouraging them to look on depression as a normal experience and on its management as a sign of tenacity and valour, as well as something that helps them regain control of their lives. The available evidence suggests that depressed men are more likely to open up about their depression where they feel that they will be trusted and respected for the seriousness of their disclosure. Men experiencing depression may be more willing to talk about their emotional difficulties than we think. We may just have to help men see why 'it's good to talk'. 


\section{Limitations in our approach}

In this scoping review, we consider a selection of the core evidence on depression in men (i.e. we did not collect or analyse primary data), the aim being to discuss and reflect on aspects of male depression. Therefore, our observations and conclusions are restricted to the understandings of male depression that have been proposed by other researchers and authors whose work we have reviewed in this paper. Our approach is further restricted by our understandings of clinical practice in the UK but we hope that our conclusions and suggestions can stimulate clinical thinking and future research.

In addition, we limited our focus to atypical symptoms of depression in men and to ways in which men may manage such atypical symptoms. We did not address men's symptoms of depression which are concordant with current diagnostic standards. Moreover, although we feel that we were able to identify and propose a number of important issues regarding atypical symptoms of depression in men and the unhelpful ways in which some depressed men cope with their depression, our discussion was based on a review of the literature rather than on a systemic review.

Furthermore, we acknowledge the potential limitation of the use of a vignette as a means of demonstrating a hypothetical case of male depression. Vignettes may lack empirical validation (Gould, 1998), nevertheless, they can successfully facilitate case conceptualisation as demonstrated by their use in clinical training (Gidengil, Linder, Beach, Setodji, Hunter, \& Mehrotra, 2016) and in research (e.g. Nadeau et al., 2016) which is the reason that we chose this approach.

Lastly, we acknowledge the potential effects that our personal theoretical orientations may have had on our discussion of the topic of male depression. All three of us take a critical perspective in the role of idealised masculinities in men's health. Therefore, our focus is on understanding social and psychological phenomena, such as male depression and masculinities, as evolving social constructs. We see mental health issues as social representations that are influenced by social context and professional practices.

Whilst we acknowledge the potential limitations in our approach, overall, we hope that our discussion of key issues in male depression can contribute to the improvement of the diagnosis of depression in men and of the effectiveness of health promotion initiatives that target depressed men.

\section{Conclusion}

In conclusion, the scientific literature acknowledges existing difficulties in the recognition of depression in men. The causes of this phenomenon appear to be complex owing to cultural influences that potentially affect the way that men experience, manage and express their depression. Males are socialised into masculinity ideals that prize stoicism and which construe help-seeking as unmasculine. Therefore, some depressed men will attempt to self-manage their depression rather 
than seek professional help. It is also likely that espoused cultural values may encourage men to construct and externalise their depression in ways that do not fit current diagnostic criteria.

Research has shown that the recognised symptoms of depression are based on expressions of depression in women. This poses difficulties in the diagnosis of depression in men and it makes it difficult for some depressed men with atypical symptoms to recognise their depression and to seek help about it. The potentially inadequate understandings of the possible manifestations of depression in men disadvantages depressed men in all aspects of their lives.

In conclusion, further research needs to clarify atypical expressions of depression and to improve the diagnosis of depression in men. Furthermore, taking into consideration some men's documented need for emotional control, research needs to improve our understanding of more effective ways in which men can be helped to address depression. Further research evidence in these areas can help change social attitudes which value men's emotional restrain and which discredit help-seeking as a valuable life skill. Lastly, vigilance in clinical practice is advised in order to appropriately identify behaviours such as anger, substance dependency, risky behaviours or working long hours as signs of depression. 


\section{References}

Addis, M. E. (2008). Gender and depression in men. Clinical Psychology: Science and Practice, 15, 153-168.

Addis, M. E., \& Mahalik, J. R. (2003). Men, masculinity, and the contexts of help seeking. American Psychologist, 58 (1), 5-14.

American Psychiatric Association (2013). Diagnostic and statistical manual of mental disorders $\left(5^{\text {th }}\right.$ ed.). Washington, DC: Author.

Apesoa-Varano, E. C., Barker, J. C., \& Hinton, L. (2015). Shards of sorrow: Older men's accounts of their depression experience. Social Science \& Medicine, 124, 1-8. http://dx.doi.org/10.1016/j.socscimed.2014.10.054

Arksey, H., \& O'Malley, L. (2005). Scoping studies: Towards a methodological framework. International Journal of Social Research Methodology, 8 (1), 19-32.

Beaumont, J., \& Lofts, H. (2013). Measuring national well-being - Health, 2013. London: Office for National Statistics. Retrieved from http://webarchive.nationalarchives.gov.uk/20160105160709/http://www.ons.gov.uk/ons/dcp171 766 310300.pdf

Brownhill, S., Wilhelm, K., Barclay, L., \& Schmied, V. (2005). 'Big Build': Hidden depression in men. Australian and New Zealand Journal of Psychiatry, 39 (10), 921-931.

Coppens, E., Van Audenhove, C., Scheerder, G., Arensman, E., Coffey, C., Costa, S., Koburger, N., Gottlebe, K., Gusmão, R., O'Connor, R., Postuvan, V., Sarchiapone, M., Sisask, M., Székely, A., Van der Feltz-Cornelis, C., \& Hegerl, U. (2013). Public attitudes toward depression and help-seeking in four European countries baseline survey prior to the OSPI-European intervention. Journal of Affective Disorders, 150, 320-329. http://dx.doi.org/10.1016/j.jad.2013.04.013

Courtenay, W. (2000). Constructions of masculinity and their influence on men's well-being: A theory of gender and health. Social Science and Medicine, 50, 1385-1401. doi:10.1016/S02779536(99)00390-1

Danielsson, U. E., Bengs, C., Samuelsson, E. \& Johansson, E. E. (2011). "My greatest dream is to be normal": The impact of gender on the depression narratives of young Swedish men and women. Qualitative Health Research, 21 (5), 612-624. doi: 10.1177/1049732310391272

Ellis, L. A., Collin, P., Hurley, P. J., Davenport, T. A., Burns, J. M., \& Hickie, I. B. (2013). Young men's attitudes and behaviour in relation to mental health and technology: Implications for the development of online mental health services. BMC Psychiatry, 13 (119). 1-10. doi: 10.1186/1471-244X-13-119

Epstein, R. M., Ruberstein, P. R., Feldman, M. D., Rochlen, A. B., Bell, R. A., Kravitz, R. L., Cilpril, C., Becker, J. D., Barmonti, P. M., \& Paterniti, D. A. (2010). "I didn't know what was wrong:" How people with undiagnosed depression recognise, name and explain their distress. Journal of General Internal Medicine, 25(9), 954-61.

Farmer, C., Farrand, P., \& O'Mahen, H. (2012). 'I am not a depressed person': How identity conflict affects help-seeking rates for major depressive disorder. BMC Psychiatry, 12 (164). doi: 10.1186/1471-244X-12-164

Fields, A. J., \& Cochran, A. V. (2011). Men and depression: Current perspectives for health care professionals. American Journal of Lifestyle Medicine, 5 (1), 92-100. doi: $10.1177 / 1559827610378347$

Galasinski, D. (2008). Men's discourses of depression. Basingstoke: Palgrave MacMillan.

Gidengil, C. A., Linder, J. A., Beach, S., Setodji, C. M., Hunter, G., \& Mehrotra, A. (2016). Using clinical vignettes to assess quality of care for acute respiratory infections. The Journal of Health Care Organisation, Provision and Financing, 53, 1-7. doi: 10.1177/0046958016636531 
Gough, B. (2016). Men's depression talk online: A qualitative analysis of accountability and authenticity in help-seeking and support formulations. Psychology of Men \& Masculinity, 17 (2), 156-164. http://dx.doi.org/10.1037/a0039456

Gough, B., Hall, M., \& Seymour-Smith, S. (2014). Straight guys do wear make-up: Contemporary masculinities and investment in appearance. In S. Roberts (Ed) Debating modern masculinities: Change, continuity, crisis? (106-124). Basingstoke: Palgrave MacMillan.

Gould, D. (1998). Using vignettes to collect data for nursing research study: How valid are the findings? Journal of Clinical Nursing, 5, 207-212. Retrieved from http://eds.a.ebscohost.com/eds/pdfviewer/pdfviewer?vid=9\&sid=5a4e2254-e7ac-4156-b189c442dc62a651\%40sessionmgr4008\&hid $=4102$

Hoy, S. (2012). Beyond men behaving badly: A meta-ethnography of men's perspectives on psychological distress and help seeking. International Journal of Men's Health, 11 (3), 202-226. doi: 10.3149jmh.1103.202

Klineberg, E., Biddle, L., Donovan, J., \& Gunnell, D. (2011). Symptom recognition and help seeking for depression in young adults: A vignette study. Social Psychiatry and Psychiatric Epidemiology, 46, 495-505. doi: 10.1007/s00127-010-0214-2

Latalova, K., Kamaradova, D., \& Prasko, J. (2014). Perspectives on perceived stigma and self-stigma in adult male patients with depression. Neuropsychiatric Disease and Treatment, 10, 13991405. http://dx.doi.org/10.2147/NDT.S54081

Lester, D. (2014). Male depression and suicide. In D. Lester, J. F. Gunn, \& P. Quinnett (Eds.), Suicide in men: How men differ from women in expressing their distress (pp. 25-33). Illinois, USA: Charles C. Thomas Publisher, Ltd.

Levant, R.F. (1998). Desperately seeking language: Understanding, assessing and treating normative male alexithymia. In W.S. Pollack \& R.F. Levant (Eds.), New psychotherapy for men (pp. 3556). New York: Wiley

Martinez-Hernaez, A., DiGiacomo, S. M., Carceller-Maicas, N., Correa-Urquiza, M., \& MartorellPoveda, M. A. (2014). Non-professional-help-seeking among young people with depression: A qualitative study. BMC Psychiatry, 14 (124). doi: 10.1186/1471-244X-14-124

McCusker, M. G., \& Galupo, M. P. (2011). The impact of men seeking help for depression on perceptions of masculine and feminine characteristics. Psychology of Men \& Masculinity, 12 (3), 275-284. doi: 10.1037/a0021071

McManus, S., Bebbington, P., Jenkins, R., \& Brugha, T. (Eds.) (2016). Mental health and wellbeing in England: Adult Psychiatric Morbidity Survey 2014. Leeds: NHS Digital. Retrieved from http://content.digital.nhs.uk/catalogue/PUB21748/apms-2014-full-rpt.pdf

Mind (n.d.). Performance matters: Mental health in elite sport. Retrieved from http://www.mind.org.uk/media/1085139/Mental-Health-and-Elite-Sport.pdf

Möller-Leimkühler, A. M. (2002). Barriers to help-seeking by men: A review of sociocultural and clinical literature with particular reference to depression. Journal of Affective Disorders, 71, 1-9.

Nadeau, M. M., Balsan, M. J., \& Rochlen, A. B. (2016). Men's depression: Endorsed experiences and expressions. Psychology of Men \& Masculinity, 17 (4), 328-335. http://dx.doi.org/10.1037/men0000027

National Health Service (2014, August 19). Clinical depression - Symptoms. Retrieved from http://www.nhs.uk/Conditions/Depression/Pages/Symptoms.aspx

O'Brien, R., Hunt, K., \& Hart, G. J. (2005). 'It's caveman stuff, but that is to a certain extent how guys still operate': Men's accounts of masculinity and help-seeking. Social Science \& Medicine, 61(3), 503-516. doi:10.1016/j.socscimed.2004.12.008

Office for National Statistics (2011). Social Trends 41: Health. London: Author. Retrieved from http://webarchive.nationalarchives.gov.uk/20160105160709/http://ons.gov.uk/ons/rel/socialtrends-rd/social-trends/social-trends-41/index.html

Office for National Statistics (2016). Measuring national well-being in the UK, domains and measures: Sept 2016. London: Author. Retrieved from 
https://www.ons.gov.uk/peoplepopulationandcommunity/wellbeing/articles/measuringnationalw ellbeing/sept2016

Oliffe, J. L., Galdas, P. M., Han, C. S. E., \& Kelly, M. T. (2012). Faux masculinities among college men who experience depression. Health, 17 (1). 75-92. doi: $10.1177 / 1363459312447256$

Oliffe, J. L., Rasmussen, B., Bottorff, J. L., Kelly, M. T., Galdas, P. M., Phinney, A., \& Ogrodniczuk, J. S. (2013). Masculinities, work, and retirement among oldher men who experience depression. Qualitative Health Research, 23 (12), 1626-1637. doi: 10.1177/1049732313509408

Piccinelli, M., \& Wilkinson, G. (2000). Gender differences in depression. British Journal of Psychiatry, 177, 486-492. doi: 10.1192/bjp.177.6.486

Ramirez, J. L., \& Badger, T. A. (2014). Men navigating inward and outward through depression. Archives of Psychiatric Nursing, 28, 21-28. http://dx.doi.org/10.1016/j.apnu.2013.10.001

Ridge, D. Emslie, C., \& White A. (2011). Understanding how men experience, express and cope with mental distress: Where next? Sociology of Health Illness, 33(1), 145-159. doi: 10.1111/j.14679566.2010.01266.x

Robertson, S., Bagnall, A. M., \& Walker, M. (2014). Evidence for a gender-based approach to mental health program: Identifying the key considerations associated with "being male". Review commissioned by the Sax Institute, on behalf of the Movember Foundation. Retrieved from http://eprints.leedsbeckett.ac.uk/1773/1/SAX_LitReview_MasculinityMentalHealth_Summary_.F INAL.pdf

Rochlen, A. B., Paterniti, D. A., Epstein, R. M., Duberstein, P., Willeford, L., \& Kravitz, R. L. (2010). Barriers in diagnosing and treating men with depression: A focus group report. American Journal of Men's Health, 4 (2), 167-175. doi: 10.1177/1557988309335823

Royal College of Psychiatrists. (2014, November). Talking to your GP about a mental health problem. Retrieved from http://www.rcpsych.ac.uk/healthadvice/treatmentswellbeing/talkingtoyourgp.aspx

Rutz, W., Von Knorring, L., Pihlgren, H., Rihmer, Z., \& Walinder, J. (1995). Prevention of male suicides: Lessons from Gotland study. Lancet, 345, 524. Retrieved from http://search.proquest.com/docview/198949405?accountid=17233.

Rutz, W., Walinder, J., Piblgren, H., Von Knorring, L, \& Rihmer, Z. (1996). Lessons from the Gotland study "Suicide and education - effects, shortcomings, challenges". European Psychiatry, 11 (4), 181s. doi: 10.1016/0924-9338(96)88506-3

Sharpley, C. F., Bitsika, V., \& Christie, D. R. H. (2014). Diagnosing 'male' depression in men diagnosed with prostate cancer: The next step in effective translational psycho-oncology interventions? Psycho-Oncology, 23, 1042-1048. doi: 10.1002/pon.3530

Sharpley, C. F., Bitsika, V., \& Christie, D. R. H. (2016). Factor structure of a combined measure of major depressive disorder and male depression in prostate cancer patients. Psycho-Oncology, 25, 475-477. doi: 10.1002/pon.3928

Sierra Hernandez, C. A., Han. C., Oliffe, J. L., \& Ogrodniczuk, J. S. (2014). Understanding helpseeking among depressed men. Psychology of Men \& Masculinity, 15 (3), 346-354. doi: 10.1037/a0034052

Sloan, C., Gough, B., \& Conner, M. T. (2010). Healthy masculinities? How ostensibly healthy men talk about lifestyle, health and gender. Psychology \& Health, 25(7), 783-803. doi: 10.1080/08870440902883204

Smith, D. J., Kyle, S., Forty, L., Cooper, C., Walters, J., Russell, E., Caesar, S., Farmer, A., McGuffin, P., Jones, I., Jones, L., \& Craddock, N. (2008). Differences in depressive symptom profile between males and females. Journal of Affective Disorders, 108, 279-284. doi: 10.1016/j.jad.2007.10.001

Tannenbaum, C. \& Frank, B. (2011). Masculinity and health in late life men. American Journal of Men's Health, 5 (3), 243-254. doi: 10.1177/1557988310384609

Vogel, D. L., \& Wade, N. G. (2009). Stigma and help-seeking. The Psychologist, 22 (1), 20-22. 
What do counsellors need to know about male depression?

Zierau, F., Bille, A., Rutz, W. \& Beck, P. (2002). The Gotland male depression scale: A validity study in patients with alcohol use disorder. Nordic Journal of Psychiatry, 56, 265-271. doi:

$10.1080 / 08039480260242750$ 